\title{
Investigating the Relationship between Lifestyle and Locus of Control in the Secondary High School Students in Bukan
}

\author{
Masoud Najari ${ }^{1}$, Fouad Babaei ${ }^{2}$, Hesam Othmani $^{3}$, Adel Karimi ${ }^{4}$, Morteza Panahi ${ }^{5}$ \\ ${ }^{1}$ PhD. Student of Educational Psychology, Teacher at University of Applied Science and Technology, \\ Bukan, Iran \\ ${ }^{2}$ MA in Consultation, Teacher at Payame Noor University, Saqez, Iran \\ ${ }^{3}$ Speech Therapist, Phezhvak Rehabilitation Center for Deaf and Hard-Hearing Children and Family, \\ Saqez, Iran \\ ${ }^{4}$ MA in Family Consultation, Allameh Tabatabaie University, Tehran, Iran \\ ${ }^{5}$ MA in Preschool Education, Allameh Tabatabaie University, Tehran, Iran
}

\begin{tabular}{|c|c|}
\hline ARTICLE INFO & ABSTRACT \\
\hline $\begin{array}{l}\text { Keywords: } \\
\text { Lifestyle } \\
\text { Locus of Control } \\
\text { Secondary high school } \\
\quad \text { period } \\
\text { Bukan }\end{array}$ & $\begin{array}{l}\text { The purpose of this study was to investigate the relationship between } \\
\text { lifestyle and locus of control in secondary high school students. The } \\
\text { population if the study consisted of all secondary high school } \\
\text { students in in Bukan. In a descriptive-correlational study, } 100 \\
\text { students were selected through cluster sampling and examined as the } \\
\text { sample. To measure the locus of control, Rater's (1966) internal and } \\
\text { external control scale was used and Lifestyle Questionnaire (LSQ) } \\
\text { was adopted to collect data. The reliability of the questionnaires in } \\
\text { this study was obtained equal to } 0.69 \text { and } 0.75 \text {, respectively, using } \\
\text { Cronbach's Alpha method. The data were analyzed using Pearson } \\
\text { correlation coefficient. The results showed that there is a statistically } \\
\text { significant difference between the lifestyle and the locus of control } \\
\text { among the students. The internal locus of control is significantly } \\
\text { related to the lifestyle (P < } 0.05 \text { ). The results of this study are in line } \\
\text { with other research. According to the findings of this research and } \\
\text { the results of previous studies, it is suggested that in relation to the } \\
\text { internal locus of control, the students are trained some skills in order } \\
\text { to enhance themselves from the external locus of control to the } \\
\text { internal one. }\end{array}$ \\
\hline
\end{tabular}

\section{Problem Statement}

Locus of control is a range of people's beliefs about having control on their own destiny $(\mathrm{Ng}$, T. W. H, 2006). In Rutter's theory, locus of control is the locus of internal and external control. In other words, individuals with an external locus of control believe that their successes and failures are driven by external and out of control factors, such as destiny, luck, powerful people, and unpredictable forces, but individuals with an internal locus of control believe that their actions and capabilities determine their successes and failures. Individuals who control their lives and have an internal locus of control experience beneficial effects in their lives, including improved desirable behavior, more psychological compatibility, and reduced physical, mental and behavioral problems (Safari and Ashouri, 2014). Individuals with an internal locus of control believe that amplifiers depend on their own behaviors and attributes. In contrast, individuals with an external locus of control believe that amplifiers depend on luck, destiny, and other people's interventions (Rockstraw, 2006). In fact, it can be stated that people with an external locus of control have positive or negative perceptions of events that are not related to

* Corresponding Author E-Mail Address: najari.masoud@yahoo.com 
individual's behavior and are beyond individual control. These people believe in chance or have an external locus of control. Individuals with an internal locus of control believe in selfdetermination, consider themselves to be rulers of their own destinies, and claim that their lives can be controlled by themselves. Locus of control is one of the main concepts in Rutter's theory. In his view, the concept of locus of control is the probability of behavior occurrence in which individuals with an internal locus of control have a generalized expectation of their behavior that depend on their own efforts; and on the other hand, people with an external locus of control have a generalized expectation that their behaviors are largely dependent on luck, chance, destiny, and external powers.

Individuals with an internal locus of control have a generalized expectation that individual efforts can cause change. While individuals with an external locus of control have a generalized expectation that individuals' efforts lead to slight and minor changes; in other words, they often feel helpless (Alami, 2005). One of the variables that can actually be linked to the locus of control is lifestyle. By assessing individuals' lifestyle, the extent of their individual and social success in their lives can be observed. Also, lifestyle is a term Adler used to refer to individual's life atmosphere. Lifestyle consists of individual's purpose, self-concept, and feelings towards others, and attitudes towards the world. Beyound anything else, he/she considers lifestyle as creativity, which is the result of confronting the limitations, barriers, contradictions and crises faced by the individual on the path to progress towards his ideal (Monica, 2015). Lifestyle is dynamic, progressive and self-created. Within a unique family atmosphere, people set goals to be achieved. Moving towards these goals will determine the patterns of relationships. Adler believes that these patterns are purposeful and powerful and are not readily expressed in terms of personal logic and attitudes that are not always clear. The relationship patterns are combined with personal goals, confidential logic, attitudes, and the family atmosphere and create a lifestyle that is taken into account as an agenda or a plan for life (Sweeney, Daniles, Minix and Lindaie, 2011).

Lifestyle is a model of individual's life that manifests itself in activities, attachments, and personal thoughts. The World Health Organization recognizes lifestyle as specified and definable behavioral patterns, resulting from the interaction between personal characteristics, social relationships, environmental conditions, and socio-economic status (Mansourian et al., 2009). Early discussions on lifestyle focused primarily on nutrition, exercise, smoking, and alcohol use, while today's understanding of lifestyle and its relationship with health has changed (Lyons \& Langille, 2000). Lifestyle can be interpreted as a set of behaviors that one uses not only to address his current needs, but also to show the particular narrative he/she has selected for his personal identity to others (Rahmatabadi and Aghabakhshi, 2006). In fact, lifestyle is a relatively constant approach through which one pursues his goals (Kaviani, 2011). This fairly constant approach involves many areas of the individual's life, including livelihoods, leisure and leisure activities, shopping and consumption patterns, the use of technological products, etc. (Mahdavi Kani, 2008). A lot of research has been done on locus of control with other variables. But there is no similar research that can be found in the context of locus of control with lifestyles among students in Iran. For this reason, the present study is considered as a new research that has been conducted in relation to two variables: locus of control and lifestyle. Shaabani Bahar, Yalfani and Qarelqi (2010) in their research named "Determining the Relationship between Locus of Control and General Health of Athletic and Non-Athletic Male Students in Tehran University" with a sample of 206 people including 103 athletes and 103 non-athletes found that there is a relationship between the locus of control and the general health of athletic and non-athletic male students. The athletic male students more internal than non-athletic male students in terms of control, and they are better than their non-athletic peers in terms of general health. Naqibi et al. (2010) in their study examined the relationship between the students' locus of control and religiousness and mental health in Mazandaran University of 
Medical Sciences and found that the students with an external locus of control show more physical complaints, more anxiety and sleep disturbances, and weaker social function and become depressed more than other people. Also, Barzegar Befrooyi, Solhpour and Imam Jomeh (2012) in their study named "The Relationship between the Locus of Control and SelfEsteem and Creativity in High School Students in Ardakan" concluded that there is a significant relationship between, students' self-esteem ND creativity at a significant level of 0.05 , but there is not any significant relationship between the students' external locus of control and creativity. In sum, the findings of this study indicate that students' high self-esteem leads to increased creativity, and also students with lower external locus of control have less creativity. In another study entitled "The Relationship between Locus of Control and SelfConcept and Perceived Stress in Pediatric Children's Mothers", Suleimani Hesar and Agha Mohammadian Sherbaf (2013) showed that there is a direct relationship between the internal locus of control and the perceived stress in pediatric children's mother and there is no direct and significant relationship between the external locus of control and the perceived stress in pediatric children's mothers. There is also a direct and significant relationship between the perceived self-concept and the perceived stress in pediatric childhood's mothers. According to the above, the present study seeks to investigate the relationship between the lifestyle and the locus of control among secondary school students and determine whether there is a relationship between the lifestyles in the students with the internal and external locus of control.

\section{Research Method}

The research method in this study is descriptive-correlational. The population of the study consists of all secondary school students in Bokan city. Multi-stage cluster random sampling was used to select the tample. At first, four different regions were selected randomly from different regions of Bukan, and from each district one school, and finally from each school, 25 students were randomly selected as the sample and the questionnaires were distributed among them. The research data were collected using two lifestyle questionnaires and Rutter's locus control scale (Rutter, 1966).

\section{Measurement Tool}

Rutter' locus of Control (1966): This questionnaire that is used to measure the locus of control was designed by Rutter in 1966 to measure people's expectations about the locus of control. The questionnaire has 29 items, each of which is answered by "Yes" or "No". This test is not related to intelligence and gender and is one of the most widely used tests for measuring adult's locus of control (Kakavand, 2002). 23 items evaluate the internal and external aspects of the locus of control and 6 other items cover the purpose of the test (Ahmadian, 1392). The participant must choose one of the sentences A or B. One of the two sentences of each clause is related to the internal control and the other is related to the external control. Individuals who score 9 or more have an external locus of control and those who score 9 or less have an internal locus of control. Ghazanfari (1992) obtained the reliability coefficient equal to 0.7 for Iranian samples using the Richardson Coder method. In the present study, the reliability coefficient was obtained 0.69 using Cronbach's alpha method.

Lifestyle questionnaire (LSQ): This questionnaire has 70 items and is graded in the Likert spectrum: (0) never, (1) sometimes (2) usually, (3) always. The aim of this study was to assess the different dimensions of lifestyle (physical health, sport and health, nutrition and weight control, disease prevention, psychological health, spiritual health, social health, drug avoidance, accident prevention, and environmental health) (Laali, Abedi and Kajbaf, 2012). Using the validity-factor analysis test in their study, Laalie' et al. (2012) confirmed the lifestyle questionnaire as a multi-dimensional tool for assessing and measuring lifestyle. The reliability of the questionnaire was also calculated using Cronbach's alpha method. Pourofoghi (2016) obtained the reliability coefficient of lifestyle questionnaire through Cronbach's alpha, which 
is 0.94 . Also, in the present study, the reliability coefficient was obtained 0.75 through Cronbach's alpha.

In addition to descriptive statistics, Pearson correlation coefficient test was also used to analyze the information obtained from the questionnaire.

\section{Findings:}

\section{A. Descriptive findings}

Table 1. Demographic findings related to the locus of control

\begin{tabular}{|l|l|l|}
\hline Groups (locus of control) & frequency & Percent \\
\hline Internal & 38 & $38 \%$ \\
\hline External & 62 & $62 \%$ \\
\hline Total & 100 & $100 \%$ \\
\hline
\end{tabular}

According to table 1, the highest frequency was for the external locus of control (62) and the lowest frequency was for the internal locus of control (38).

Table 2. Descriptive findings of the lifestyle variable

\begin{tabular}{|l|l|l|}
\hline Components & Mean & Standard Deviation \\
\hline Physical health & 21.53 & 5.69 \\
\hline sport & 14.22 & 2.57 \\
\hline Weight control & 14.46 & 3.18 \\
\hline Disease prevention & 13.33 & 2.52 \\
\hline Psychological health & 14.24 & 2.19 \\
\hline Spiritual health & 13.32 & 2.89 \\
\hline Social health & 13.21 & 2.67 \\
\hline Drug prevention & 12.53 & 2.11 \\
\hline Accident prevention & 13.65 & 1.94 \\
\hline Environmental health & 11.32 & 2.42 \\
\hline Total & 132.27 & 3.12 \\
\hline
\end{tabular}

\section{B. Inferential findings}

Table 3. Correlation between lifestyle and internal locus of control

\begin{tabular}{|l|l|c|c|}
\hline Pearson correlation & coefficient test & Lifestyle & Locus of control \\
\hline \multirow{3}{*}{ Lifestyle } & Pearson Coefficient test & 1 & 0.397 \\
\cline { 2 - 4 } & Significance & & 0.05 \\
\cline { 2 - 4 } & Number & 38 & 38 \\
\hline \multirow{3}{*}{ Locus of control } & Pearson coefficient test & 0.397 & 1 \\
\cline { 2 - 4 } & Significance & 0.05 & 38 \\
\cline { 2 - 4 } & number & 62 & \\
\hline
\end{tabular}

Table 4. Correlation between lifestyle and external locus of control

\begin{tabular}{|l|l|c|c|}
\hline Pearson correlation & coefficient test & Lifestyle & Locus of control \\
\hline \multirow{3}{*}{ Lifestyle } & Pearson Coefficient test & 1 & 0.259 \\
\cline { 2 - 4 } & Significance & & 0.05 \\
\cline { 2 - 4 } & Number & 62 & 62 \\
\hline \multirow{3}{*}{ Locus of control } & Pearson coefficient test & 0.259 & 1 \\
\cline { 2 - 4 } & Significance & 0.05 & 62 \\
\cline { 2 - 4 } & number & 62 & \\
\hline
\end{tabular}


Pearson correlation coefficient was used to investigate the relation between lifestyle and internal locus of control and between lifestyle and external locus of control. The results showed that there is a significant relationship between two variables of internal locus of control $(\mathrm{r}=$ 0.397 and $\operatorname{sig}=0.05)$ and external locus of control $(r=0.259$ and $\operatorname{sig}=0.05)$ and both hypotheses of the study are confirmed.

\section{Conclusion}

This study was conducted with the aim of investigating the relationship between lifestyle and locus of control among secondary high school students in Bukan. The hypotheses of the research that there are significant relationships between lifestyle and internal locus of control as well as between lifestyle and external locus of control were confirmed.

According to the findings of this research, lifestyle components can be predicted using internal and external locus of control. The locus of control refers to the extent of individual's belief in rewards earned through personal efforts. Individuals described as "characters with internal locus of control" believe that the reinforcement they receive is controlled by their own behaviors and attitudes, but those who have the character of the external locus of control imagine the rewards that they receive are given by others, fate, or chance. The locus of control can be trained and in fact this training is directly related to parents' behavior. Since students with an internal locus of control can be more successful in all areas of study, occupation, etc., and more efficient people, it is suggested that the schools provide the resources and facilities necessary for students to grow and develop and teachers in this context can educate students with high self-esteem and self-efficacy for the community and use new teaching methods to express the students' presence and move them from external locus of control to internal locus of control. Also, guiding teachers towards the use of proper education and correct attitude towards the internal locus of control and its consequences in society can be considered as a good tool for the promotion and growth of society and the holding of workshops in both fields of research variables, i.e. lifestyle and locus of control, can be important and its impact on the students' lives can be observed. Also, considering that lifestyle has a lot of components, its relationship with other variables can be investigated and developed as a model and its results in schools help students in terms of educational and behavioral goals. Finally, the present study was limited to secondary school students in Bukan, and we should be cautious in generalizing the findings. It is suggested that a similar study be carried out in other cities and statistical communities in order to obtain the results compared to the findings of this study. Therefore, repeating this research in other age groups and educational levels also makes it possible to generalize the results more confidently.

\section{References}

Ahmadian, N. (2013). The relationship between personality features and locus of control and exam anxiety in high school students of Birjand. Journal of Educational Psychological Studies, 10 (18), 1-20.

Barzegar Befrooyi, F., Salehpour, M., \& Imam Jomeh, S. M. (2012). Investigating the Relationship between the Locus of Control and Self-Esteem and Creativity in High School Students in Ardakan. School Psychology Quarterly, 3 (4), 6-21, 2012.

Pourofogi, F. (2016). The role of lifestyles, social perceptions, and family relationships in predicting young teachers' marital satisfaction. School Psychology Quarterly, 5 (2), 20-38.

Rahmatabadi, E., \& AghaBakhshi, H. (2006). Youth's lifestyle and social identity. Social Welfare Quarterly, 5 (20), 235-256.

Suleimani Hesar, M., \& Agha Mohammadian Sherbaf, H. R. (2013). The Relationship between Locus of Control and Self-Concept and Perceived Stress in Pediatric Children's Mothers. Journal of Psychological Health Principles, 15 (1), 35-44. 
Shaabani Bahar, G. R., Yalfani. A., \& Qarelqi. S. (2010). Determining the Relationship between Locus of Control and General Health of Athletic and Non-Athletic Male Students in Tehran University. Sport Management Quarterly, 7, 43-59.

Safarian, M. R., \& Ashouri, J. (2014). Investigating the relationship between locus of control, personality characteristic, self-esteem, and religious orientation and desired discipline behavior. Journal of Mental Health Principle, 3 (16), 476-473, 2014.

Kaviani, M. (2011). Quantification and measurement of Islamic lifestyle. Psychology and Religion, 4 (2), 27-44.

Laali, M., A. Abedi M., \& Kajbaf, M. B. (2012). Making and validating the Life Style Questionnaire (LSQ). Psychological Research, 15 (1), 26-39.

Mansourian, M., Ghorbani, M., Soleimani, M. A., Masoudi, R., Rahimi, E., and Asayesh, H. (2009). Investigating the relationship between lifestyle and factors affecting it among university students in Gorgan. Journal of Pars University of Medical Sciences, 7 (1), 62-71.

Mahdavi Kani, M. S. (2008). Religion and Lifestyle. Tehran: Imam Sadiq University Press.

Naqibi, S. A. H., Hosseini, S. H., Yazdani, J., Shafiei, S. R., \& Khorasani, F. (2010). Relationship between the students' locus of control and religiousness and mental health in Mazandaran University of Medical Sciences. Journal of Religion and Health, 1 (1), 1-8, 2010.

Lyons, R., Langille, L. (2000). Healthy life style: strengthening the effectiveness of life style approaches to improve health. The Canadian consortium of health promotion centers.

Rockstraw, L. J. (2006). Self- efficacy, locus of control and the use of simulation in undergraduate nursing skills acquisition. $\mathrm{PhD}$ dissertation. Drexel University.

Ng, T. W. H., Sorensen, K. L., \& Eby, T. 1. (2006). Locus of control at work: a Meta-analysis. Journal of organizational Behaviour, 27(8),1057- 1087. 